\title{
Biomimetic Method for Production of Magnetic Hydroxyapatite Microcapsules for Enzyme Immobilization
}

\author{
Masaya Yamamoto $^{1}$, Takeshi Yabutsuka ${ }^{1 *}$, Shigeomi Takai ${ }^{1}$ and Takeshi Yao ${ }^{2}$ \\ 1 Department of Fundamental Energy Science, Graduate School of Energy Science, Kyoto University, \\ Yoshida, Sakyo-ku, Kyoto 606-8501, Japan \\ 2 National Institute of Technology, Kagawa College, 355 Chokushi-cho, Takamatsu, Kagawa 761-8058, Japan \\ * Corresponding author: Fax: 81-75-753-9115, e-mail: yabutsuka@energy.kyoto-u.ac.jp
}

\begin{abstract}
We fabricated hydroxyapatite microcapsules encapsulating $\gamma-\mathrm{Fe}_{2} \mathrm{O}_{3}$ particles by biomimetic method using Apatite Nucleus and SBF. In general, hydroxyapatite adsorbs many types of biomolecules like enzyme on its surface. In the present study, to examine enzyme immobilization property of the microcapsules, we immobilized seven types of

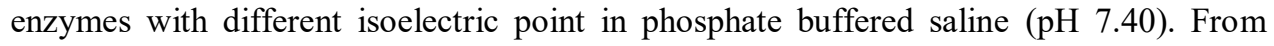
results of material analyses, we successfully fabricated hydroxyapatite microcapsules encapsulating $\gamma-\mathrm{Fe}_{2} \mathrm{O}_{3}$ with lower crystallinity than that of stoichiometric hydroxyapatite. In comparison with monoclinic hydroxyapatite, the microcapsules adsorbed more enzymes due to the larger specific surface area. As enzyme in the buffer was moderately charged, immobilization efficiency showed the highest value. It is suggested that immobilization efficiency was affected by $\mathrm{pI}$ of enzyme and that enzyme immobilization occurred by not only electrical double layer interaction but also ion interaction and other interactions.
\end{abstract}

Key words: Hydroxyapatite, Magnetic property, Enzyme immobilization, Isoelectric point, Biomimetic method

\section{INTRODUCTION}

Hydroxyapatite constitutes approximately $69 \%$ of human living bones. The crystalline of hydroxyapatite shows needle-like or plate-like and it has a-plane and c-plane. The a-plane of hydroxyapatite is positively charged due to calcium ion and the c-plane is negatively charged due to phosphate groups and hydroxide ion [1, 2]. Hydroxyapatite has an ability to adsorb biomolecules like protein and enzyme. Protein molecules are locally charged negatively and positively by the charged amino acid residues such as aspartic acid, glutamic acid, lysine, arginine and histidine [3]. Therefore, it is suggested that adsorption occurs by electrostatical interaction between protein and hydroxyapatite [4-6].

When the $\mathrm{pH}$ or temperature of simulated body fluid (SBF) [7-9] is raised, fine particles of amorphous calcium phosphate are precipitated. In our recent studies, the fine particle highly induces hydroxyapatite formation in SBF and named it Apatite Nucleus (AN) [10].

In our previous studies, we fabricated some kinds of hydroxyapatite microcapsules covering core particles through hydroxyapatite formation induced by AN. The core particles we used were Ag microspheres [11], silicagel microspheres [12], magnetite microspheres [13] and maghemite $\left(\gamma-\mathrm{Fe}_{2} \mathrm{O}_{3}\right)$ nanoparticles [14]. $\gamma-\mathrm{Fe}_{2} \mathrm{O}_{3}$ has ferrimagnetism and is chemically stable. The hydroxyapatite microcapsules encapsulating $\gamma-\mathrm{Fe}_{2} \mathrm{O}_{3}$ particles can immobilize urease on their surfaces and we can collect them by applying magnetic field. Furthermore, the urease immobilized on the microcapsules can hydrolyze urea [15].

Enzyme immobilization as we immobilized urease enhances $\mathrm{pH}$ and thermal stability, and allows us to reuse enzyme by separation of immobilized enzyme and products. Compared to inorganic catalyst, enzyme is environmentally friendly and thus the enzyme immobilization microcapsules we fabricated are promising environmental materials. In this study, to examine the enzyme immobilization property of the microcapsules, we immobilized seven types of enzymes with different isoelectric point (pI) on the surfaces of the microcapsules.

\section{MATERIALS AND METHODS}

2.1 Preparation of SBF and Apatite Nucleus

We prepared SBF by Kokubo's method [7-9]. We dissolved reagent-grade $\mathrm{NaCl}$ (Wako Pure Chemical Industries, Ltd., Japan), $\mathrm{NaHCO}_{3}, \mathrm{KCl}$ (Hayashi Pure Chemical Ind.,Ltd., Japan), $\mathrm{K}_{2} \mathrm{HPO}_{4} \cdot 3 \mathrm{H}_{2} \mathrm{O}$ (nacalai tesque, Japan), $\mathrm{MgCl}_{2} \cdot 6 \mathrm{H}_{2} \mathrm{O}, \mathrm{CaCl}_{2}$ and $\mathrm{Na}_{2} \mathrm{SO}_{4}$ (Hayashi Pure Chemical Ind.,Ltd., Japan) in distilled water and buffered it at $\mathrm{pH} 7.40$ with tris(hydroxymethyl)aminomethane (Hayashi Pure Chemical Ind.,Ltd., Japan) and $1 \mathrm{M} \mathrm{HCl}$ at $36.5^{\circ} \mathrm{C}$.

The $\mathrm{pH}$ value of SBF was raised to 8.40 by dissolution of tris(hydroxymethyl)aminomethane at $25.0{ }^{\circ} \mathrm{C}$. Then, microwave at $700 \mathrm{~W}$ was irradiated to the SBF for $9 \mathrm{~min}$ and ANs were precipitated in the SBF. It was collected by percolation using a nitrocellulose membrane filter with $50 \mathrm{~nm}$ for average pore size (Merck Millipore, USA), rinsed with distilled water, and dried at $36.5^{\circ} \mathrm{C}$.

\subsection{Preparation of phosphate buffered saline}

We prepared phosphate buffered saline (PBS) by dissolving reagent-grade $\mathrm{NaCl}(137 \mathrm{mM}), \mathrm{KCl}(2.68$ $\mathrm{mM}), \quad \mathrm{Na}_{2} \mathrm{HPO}_{4} \cdot 12 \mathrm{H}_{2} \mathrm{O} \quad(10.0 \mathrm{mM}$, Wako Pure 
Chemical Industries, Ltd., Japan) and $\mathrm{KH}_{2} \mathrm{PO}_{4}(1.76$ $\mathrm{mM}$, Wako Pure Chemical Industries, Ltd., Japan) and buffering at $\mathrm{pH} 7.40$ with $1 \mathrm{M} \mathrm{HCl}$ at $36.5^{\circ} \mathrm{C}$.

2.3 Fabrication and analyses of magnetic hydroxyapatite microcapsules

Ten mg of $\gamma-\mathrm{Fe}_{2} \mathrm{O}_{3}$ particles (Aldrich, USA, particle diameter $<50 \mathrm{~nm}$ ) and $30 \mathrm{mg}$ of ANs were added in $1000 \mathrm{ml}$ of distilled water and dispersed with ultrasonic vibration for $10 \mathrm{~min}$. By this treatment, $\mathrm{ANs}$ were attached on the surfaces of $\gamma-\mathrm{Fe}_{2} \mathrm{O}_{3}$ particles and immersed them in SBF at pH 7.60 at $36.5{ }^{\circ} \mathrm{C}$ for 24 hours. Hydroxyapatite was formed by $\mathrm{ANs}$ and we obtained magnetic hydroxyapatite microcapsules covering whole surafaces of $\gamma-\mathrm{Fe}_{2} \mathrm{O}_{3}$ particles. They were collected by percolation using a nitrocellulose membrane filter with $300 \mathrm{~nm}$ for average pore size (Merck Millipore, USA), rinsed with distilled water, and dried at $36.5^{\circ} \mathrm{C}$. The surface structure and size of the microcapsules were observed by field emission scanning electron microscopy (FE-SEM; SU6600, Hitachi High-Technologies, Japan). The X-ray diffraction (XRD) patterns of samples were obtained by Ultima IV (Rigaku, Japan) with $\mathrm{Cu}-\mathrm{K} \alpha$ radiation. The elemental composition of the microcapsules were analyzed by energy dispersive X-ray analysis (EDX; XFlash ${ }^{\circledR} 5010$, Bruker, Germany) and fourier transform infrared spectroscopy (FT-IR; FT-720, HORIBA, Japan).

2.4 Enzyme immobilization on the magnetic hydroxyapatite microcapsules

The suspension of the microcapsules $(4 \mathrm{mg} / \mathrm{ml}$ in PBS) was treated by ultrasonic vibration for $5 \mathrm{~min}$. The same volume of enzyme solution ( $2 \mathrm{mg} / \mathrm{ml}$ in PBS) was added to the suspension of the microcapsules and mixed well for 24 hours. The enzymes used in this study were pepsin (Aldrich, USA, $\mathrm{pI}=2.6$ ), invertase (Aldrich, USA, $\mathrm{pI}=3.8$ ), urease (Wako Pure Chemical Industries, Ltd., Japan, $\mathrm{pI}=5.0$ ), peroxidase (Wako Pure Chemical Industries, Ltd., Japan, $\mathrm{pI}=7.2), \quad \alpha$-chymotrypsin (Aldrich, USA, pI=8.75), trypsin (Aldrich, USA, $\mathrm{pI}=10.1$ ) and lysozyme (Wako Pure Chemical Industries, Ltd., Japan, pI=11.0). The microcapsules after mixing were collected by centrifugation and the concentration of enzyme in the supernatant was determined by Bradford's method [16] with ultraviolet and visible spectrophotometer (UV-VIS; U-5100, Hitachi HighTechnologies, Japan). Bovine serum albumin (nacalai tesque, Japan) was used as a standard. The immobilization efficiency was calculated by following equation,

$$
\text { Immobilization efficiency [\%] }=\frac{\mathrm{C}_{0}-\mathrm{C}_{1}}{\mathrm{C}_{0}} \times 100
$$

where $C_{0}$ is the initial concentration of enzyme $(\mathrm{mg} / \mathrm{ml})$ and $\mathrm{C}_{1}$ is the enzyme concentration after immobilization $(\mathrm{mg} / \mathrm{ml})$. The above-mentioned experiment using commercially available monoclinic hydroxyapatite powder (Wako Pure Chemical Industries, Ltd., Japan, 4 $\mathrm{mg} / \mathrm{ml}$ in PBS) instead of the microcapsules was conducted for comparison. All measurements were conducted in triplicate and standard errors were calculated.

\section{RESULTS AND DISCUSSION}

3.1 Analyses of the magnetic hydroxyapatite microcapsules

Fig.1 shows the SEM image of the hydroxyapatite microcapsules fabricated by using ANs and SBF. It can be seen that the whole surface of the microcapsule was coated by needle-like crystallites and the diameter of the microcapsule was $1-2 \mu \mathrm{m}$ similar to our previous studies $[14,15]$.

As shown in EDX profile (Fig.2), peaks of calcium and phosphorous derived from a component of calcium phospate, and peaks of $\mathrm{Fe}$ derived from a component of $\gamma-\mathrm{Fe}_{2} \mathrm{O}_{3}$, were observed. The FT-IR spectra of $\gamma-\mathrm{Fe}_{2} \mathrm{O}_{3}$ particles, the microcapsules and monoclinic hydroxyapatite are shown in Fig.3. In the FT-IR spectrum of monoclinic hydroxyapatite (Fig.3C), characteristic bands assigned to the phosphate groups were observed at 1095, 1060, 1024 and $960 \mathrm{~cm}^{-1}$ due to the stretching mode of the P-O bond. The FT-IR spectrum of the microcapsules (Fig.3B), the bands assigned to the phosphate groups were newly observed at $1105,1051,1027$ and $958 \mathrm{~cm}^{-1}$ in comparison with that of the untreated $\gamma-\mathrm{Fe}_{2} \mathrm{O}_{3}$ particles (Fig.3A). From the EDX profile and the FT-IR spectra data, it is indicate that calcium phosphate was formed on the surface of $\gamma-\mathrm{Fe}_{2} \mathrm{O}_{3}$ particles in SBF and the $\gamma-\mathrm{Fe}_{2} \mathrm{O}_{3}$ particles were encapsulated with the calcium phosphate.

The XRD patterns of (A) the microcapsules and (B) the untreated $\gamma-\mathrm{Fe}_{2} \mathrm{O}_{3}$ particles are presented in Fig.4. In the diffraction pattern of the microcapsules, new diffraction peaks of hydroxyapatite were appeared at 22, $28,32,35,40,46$ and $49^{\circ}$ in addition to that of the untreated $\gamma-\mathrm{Fe}_{2} \mathrm{O}_{3}$ particles. The peaks of hydroxyapatite exhibited broad shape, implying that hydroxyapatite with lower crystallinity than that of stoichiometiric hydroxyapatite covered $\gamma-\mathrm{Fe}_{2} \mathrm{O}_{3}$ particles while soaking in SBF.

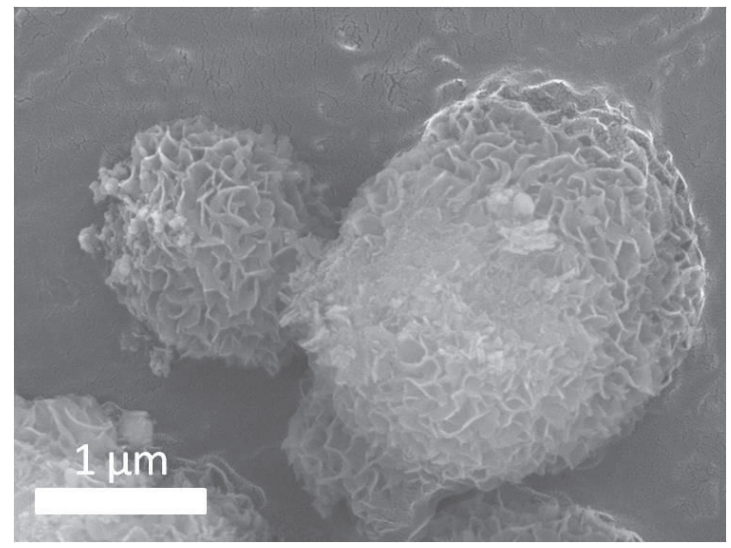

Fig.1 SEM image of the hydroxyapatite microcapsules fabricated by using ANs and SBF at pH 7.60. 


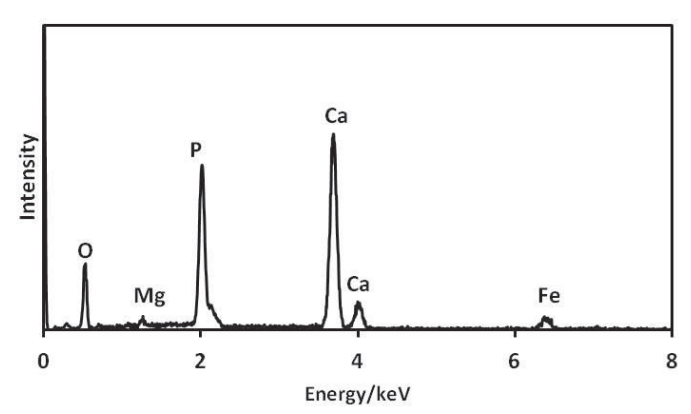

Fig.2 EDX profile of the hydroxyapatite microcapsules fabricated by using ANs and SBF at $\mathrm{pH} 7.60$.

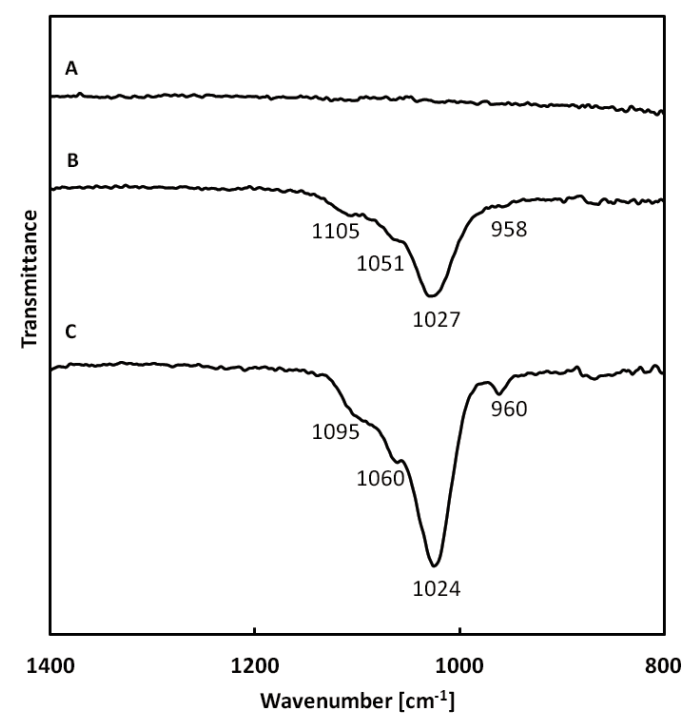

Fig.3 FT-IR spectra of (A) $\gamma-\mathrm{Fe}_{2} \mathrm{O}_{3}$ particles, (B) the hydroxyapatite microcapsules and (C) monoclinic hydroxyapatite.

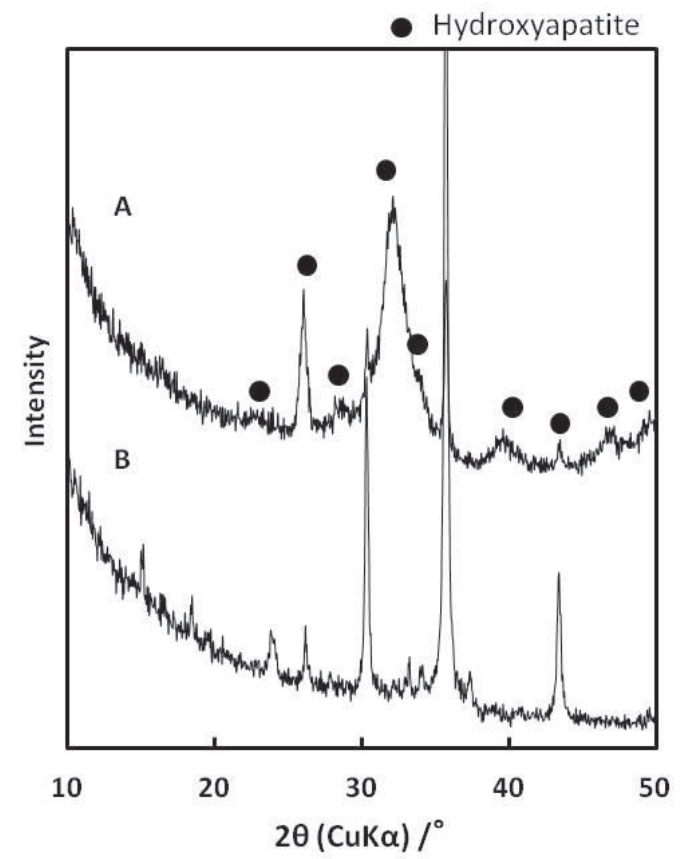

Fig.4 XRD patterns of (A) the microcapsules and (B) the untreated $\gamma-\mathrm{Fe}_{2} \mathrm{O}_{3}$ particles.
3.2 Enzyme immobilization of the magnetic hydroxyapatite microcapsules in two types of buffers

The seven types of enzymes which have various isoelectric point $(\mathrm{pI}=2.6,3.8,5.0,7.2,8.75,10.1$ and 11.0) were immobilized on the microcapsules and monoclinic hydroxyapatite in PBS and carbonate/bicarbonate buffer. Fig.5 shows enzyme immobilization efficiency of (A) monoclinic hydroxyapatite and (B) the microcapsules in PBS as a function of $\mathrm{pI}$, respectively. In both figures, $\alpha$-chymotrypsin was immobilized the most and it can be seen that there is no relationship between immobilization efficiency and $\mathrm{pI}$ of enzymes. In addition, it is indicated that the amount of enzyme on the microcapsules was more than that of monoclinic hydroxyapatite due to the larger specific surface area of the microcapsules [15]. Then we introduced the absolute value of the difference between $\mathrm{pH}$ of the enzyme solution and $\mathrm{pI}$ of enzyme (|pH-pI|) instead of $\mathrm{pI}$ as the x-axis (Fig.6 (A), (B)). When the value of $|\mathrm{pH}-\mathrm{pI}|$ is closed to zero, free enzyme in the solution is electrostatically neutral and as the value of $|\mathrm{pH}-\mathrm{pI}|$ becomes larger, enzyme is strongly charged. As shown in Fig.6 (A), (B), immobilization efficiency did not increase or decrease linearly but had the maximum value. In other words, when the enzyme was moderately charged ( $|\mathrm{pH}-\mathrm{pI}|=1 \sim 2)$, it was immobilized the most on the microcapsules and monoclinic hydroxyapatite. It is suggested that enzyme immobilization occurred by not only electrical double layer interaction but also other interaction such as van der Waals force and locally ion interaction.

The conformational change on immobilized enzymes is an important factor in enzyme immobilization. They occur enzyme denaturation and inactivation. It is reported that the secondary structure of enzyme immobilized on needle-like hydroxyapatite was well maintained [5]. In this study, we immobilized enzymes on the microcapsules which were covered by needle-like hydroxyapatite crystallites. Therefore, we considered that the conformational changes of the enzymes immobilized on the microcapsules did not occur. 

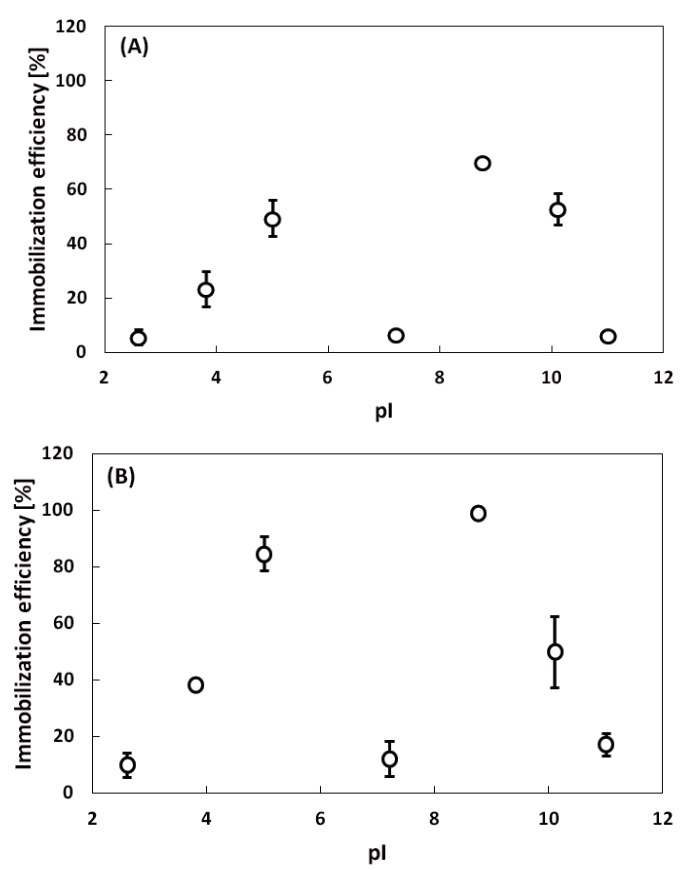

Fig.5 Enzyme immobilization efficiency of (A) monoclinic hydroxyapatite and (B) the microcapsules in PBS as a function of $\mathrm{pI}$.
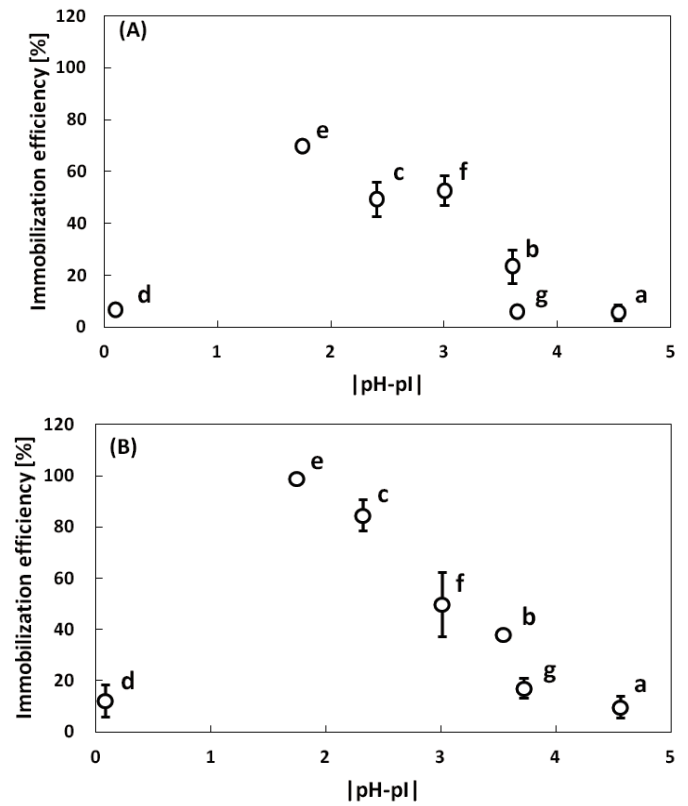

Fig.6 Enzyme immobilization efficiency of (A) monoclinic hydroxyapatite and (B) the microcapsules in PBS as a function of $|\mathrm{pH}-\mathrm{pI}|$. (a) pepsin, (b) invertase, (c) urease, (d) peroxidase, (e) $\alpha$-chymotrypsin, (f) trypsin and $(\mathrm{g})$ lysozyme.

\section{CONCLUSION}

We fabricated hydroxyapatite microcapsules encapsulating $\gamma-\mathrm{Fe}_{2} \mathrm{O}_{3}$ and immobilized seven types of enzymes with different $\mathrm{pI}$ in PBS. Immobilization efficiency of each enzyme on the microcapsules was higher than that of each enzyme on monoclinic hydroxyapatite because of the larger specific surface area of the microcapsules. There is no relationship between immobilization efficiency and $\mathrm{pI}$ of enzymes and then we introduced the absolute value of the difference between $\mathrm{pH}$ of the enzyme solution and $\mathrm{pI}$ of enzyme (|pH-pI|) instead of pI. When the enzyme was moderately charged, it was immobilized the most. It is suggested that enzyme immobilization occurred by not only electrical double layer interaction but also other interactions.

\section{REFERENCES}

[1] T. Kawasaki, S. Takahashi and K. Ikeda, Eur. J. Biochem., 152, 361-371 (1985).

[2] T. Kawasaki, K. Ikeda, S. Takahashi and Y. Kuboki, Eur. J. Biochem., 155, 249-257 (1986).

[3] H. X. Liu, R. S. Zhang, X. J. Yao, M. C. Liu, Z. D. $\mathrm{Hu}$ and B. T. Fan, J. Chem. Inf. Comput. Sci., 44, 161-167 (2004).

[4] E. Mavropoulos, A. M. Costa, L. T. Costa, C. A. Achete, A. Mello, J. M. Granjeiro and A. M. Rossi, Colloids Surf. B: Biointerfaces, 83, 1-9 (2011).

[5] Y. Ma, J. Zhang, S. Guo, J. Shi, W. Du, Z. Wang, L. Ye, W. Gu, Mater. Sci. and Eng. C, 68, 551-556 (2016). [6] A. Oyane, T. Ootsuka, K. Hayama, Y. Sogo, A. Ito, Acta Biomaterialia , 7, 2969-2976 (2011).

[7] T. Kokubo, H. Kushitani, S. Sakka, T. Kitsugi, T. Yamamuro, J. Biomed. Mater. Res., 24, 721-734 (1990). [8] T. Kokubo, H. Takadama, Biomaterials, 27, 2907-2915 (2006).

[9] H. Takadama, T. Kokubo, In vitro evaluation of bone bioactivity, in: T. Kokubo (Ed.), Bioceramics and their clinical applications, Woodhead Publishing, Cambridge, 2008, pp. 165-182.

[10] T. Yao, M. Hibino, S. Yamaguchi H. Okada, Japanese Patent 5261712 (2013), U.S. Patent 8178066 (2012).

[11] T. Yabutsuka, S. Tsuboi, M. Hibino, T. Yao, Key Eng Mater., 361-363, 1199-1202 (2008).

[12] S. Yamane, T. Yabustuka, M. Hibino, T. Yao, Fabrication of encapsulated silicagel microsphere with hydroxyapatite for sustained-release, Key Eng Mater., 396-398, 519-522 (2009).

[13] T. Yabutsuka, T. Yao, Energy Procedia, 9, 532-538 (2011).

[14] S. Kumazawa, D. Hisashuku, T. Yabutsuka, T. Yao, Key Eng. Mater., 587, 160-164 (2014).

[15] T. Yabutsuka, S. Kumazawa, D. Hisashuku, H. Mizutani, Key Eng. Mater., 696, 259-264 (2016).

[16] M. Bradford, Anal. Biochem., 72, 248-254 (1976).

\section{ACKNOWLEDGEMENT}

This work was partly supported by Grant-in-Aid from Kansai Research Foundation for Technology Promotion.

(Received January 31, 2018; Accepted March 19, 2018; Published Online June 1, 2018) 